\title{
Walking beyond the Socioeconomic Status in an Objectively and Perceptually Walkable Pedestrian Environment
}

\author{
Zeynep Toker \\ Urban Studies and Planning Department, California State University, 18111 Nordhoff Street, Northridge, CA 91330-8259, USA \\ Correspondence should be addressed to Zeynep Toker; ztoker@csun.edu
}

Received 20 October 2014; Accepted 22 January 2015

Academic Editor: Thomas Panagopoulos

Copyright (C) 2015 Zeynep Toker. This is an open access article distributed under the Creative Commons Attribution License, which permits unrestricted use, distribution, and reproduction in any medium, provided the original work is properly cited.

\begin{abstract}
An extensive body of literature suggests that physical environment, physical activity, and socioeconomic status (SES) are intrinsically linked to each other and to weight related health problems. In this study, the role of objective and perceived pedestrian environment characteristics (microscale measures) was explored in relation to people's recreational walking patterns in two neighborhoods with opposite SES. A total of 441 street segments were assessed and a total of 133 questionnaires were conducted. The findings suggest that recreational walking can take place beyond a neighborhood's suggested SES when objective and especially perceived microscale characteristics (pedestrian environment) are favorable.
\end{abstract}

\section{Introduction}

One component of the complex relationship between cities and public health is the interaction between physical environment characteristics and people's physical activity patterns. The literature on this topic, mainly led by the public health discipline, has established that physical environment characteristics might hinder or foster people's physical activities levels (e.g., [1-3]).

However, this relationship is deeply influenced by socioeconomic status (SES): physical inactivity leads to obesity, and both these factors are disproportionately prevalent among the low SES groups in the United States [4-6]. The gap is particularly wide for recreational physical activity between low and high SES groups [7]. Moreover, certain physical environment characteristics, such as high density layout $[8,9]$ and poorly maintained streets, [10] are more common in low SES neighborhoods.

How physical environment is operationalized influences how the relationship between physical activity and physical environment is described. Two types of measures have been utilized to operationalize physical environment characteristics: macroscale measures (neighborhood characteristics) and microscale measures (pedestrian environment characteristics). Macroscale measures, especially land use mix, street connectivity, and residential density, are the popularly utilized measures in the literature. Conversely, microscale measures, which include pedestrian infrastructure, safety, and aesthetics, have been less popular mostly due to the laborintensive data collection methods required for systematically recording such characteristics in large geographic areas. The elements of both these scales are addressed through objective and perceived measures in the literature. Varying levels of evidence and little agreement between scales and types of measures have resulted in both scales of measures (micro and macro) and types of measures (objective and perceived) playing a role in people's recreational walking patterns (e.g., [11-15]).

For several reasons it is difficult to identify an effective point of intervention within this unsystematic framework. First, the set of physical environment characteristics associated with recreational walking is different from the set which is associated with utilitarian walking $[15,16]$. Second, there is poor agreement between macro- and microscale measures [8], as well as between objective and perceived measures of these scales $[17,18]$. Third, the role of SES is not clear in this framework. For example, although low SES neighborhoods are generally found to be more walkable according to the macroscale measures, they are also places where people walk less due to the problems related to microscale measures, such as poor safety (traffic and crime) or poor pedestrian infrastructure (sidewalk and street characteristics) [8]. 
The purpose of this study is to explore the role of objective and perceived microscale characteristics in people's recreational walking patterns in two neighborhoods with opposite SES. The following research questions have guided this study.

(1) How do different SES neighborhoods vary in terms of observed walking, reported recreational walking, and observed and perceived microscale characteristics?

(2) What are the microscale characteristics which are fostering or hindering recreational walking behavior?

(3) How are objective and perceived microscale characteristics aligned?

This study contributes to a large body of literature by exploring the role of SES and objective and perceived microscale characteristics in relation to observed walking and reported recreational walking. Improving microscale characteristics by addressing perceived and objective microscale measures is potentially a powerful intervention to the physical environment as a short term solution [8] in order to facilitate recreational walking among the residents of a neighborhood.

\section{Literature Review: Physical Activity, Physical Environment, and SES}

Physical environment characteristics have been broadly studied in relation to physical activity. Using various methods, a combination of public health, city planning, and leisure studies literature, [19] has developed evidence that overall health is affected by the relationship between physical environment characteristics and physical activity, measured predominantly through weight-related criterion. Moreover, many of these studies in the literature have been reviewed for meta-analyses to offer a comprehensive understanding of that claimed relationship between physical environment characteristics and physical activity (e.g., $[1,2,19,20]$ ). However, the results of these studies seem to be inconclusive to the exact role of physical environment characteristics in fostering or hindering people's physical activities.

The problem seems to be embedded in three areas. First, in terms of physical activity, various forms of walking, such as recreational walking (e.g., for leisure and exercise) and utilitarian walking (e.g., for transport, work, school, and shopping), are associated with different sets of physical environment characteristics. Second, operationalization of physical environment characteristics, which determine a particular setting's walkability level, presents an unusual predicament for researchers who must choose between less reliable proxies available in large secondary data sets (e.g., median home age) and more reliable measures that require primary data collection (e.g., sidewalk quality). The problem presents itself in the form of disagreement between macro- and microscale measures and between perceived and objective measures of both scales. Third, the role of SES in relation to physical environment and physical activity is unclear. Low SES neighborhoods are more walkable according to the macroscale measures but less walkable according to microscale measures.
Also, low SES groups walk less for recreation and more for utilitarian purposes.

The literature review for this study is organized addressing different purposes attached to physical activity, different types and scales of physical environment characteristics, and the complex role of SES. A review of literature suggests SES directly influences physical activity levels and also indirectly influences these levels by means of physical environment characteristics (Figure 1).

\subsection{Purpose of Physical Activity in relation to Physical Environ-} ment: Recreational and Utilitarian Walking. In the literature, physical activity variables range from general physical activity to purpose and mode-specific transport. When physical activity is measured in the generic sense, it includes walking, cycling, and aerobic exercise $[1,21]$. These studies explore the relationship between physical environment characteristics and physical activity either by comparing the objective and perceived measures of the physical environment in relation to physical activity (e.g., [21]) or by compiling studies in the literature for a comprehensive understanding of that relationship (e.g., [1]). However, due to the nature of various types of physical activity and various purposes attached to them, different types (perceived and objective) and scales (micro and macro) of physical environment characteristics foster or hinder different types of physical activity [16].

Both nonmotorized travel [22] and aerobic exercise [23] are linked to physical environment characteristics. Cervero and Kockelman [22] show solid associations between physical environment characteristics and choice of nonmotorized travel. Studying both bicycling and walking behavior also yields associations between physical environment characteristics and physical activity [14, 24]. However, contextual differences between the two produce evidence which suggests that different physical environment characteristics are associated with physical activity in places such as Colombia [24] and that poor agreement between objective and perceived measures of these physical environment characteristics weakens that association [14].

With walking behavior in general (recreational and utilitarian walking combined), the objective measures of physical environment characteristics are shown to have associations [11, 13, 25-28]. However, the poor agreement between objective and perceived measures of physical environment characteristics for walking behavior in general undermines that association $[17,18]$.

Hoehner et al. [15] report that utilitarian walking and recreational walking are associated with different perceived and objective environmental characteristics. For example, Gebel et al. [29] state that when the objectively highly walkable environment is perceived as low, this decreases the level of utilitarian walking. Similarly, Saelens et al. [30] indicate that the objective measures of physical environment characteristics have an association with utilitarian walking but not with recreational walking.

Utilitarian walking is associated with objective measures of physical environment [31-33]. Similarly when isolated, walking to work [9, 34], walking for errands [35], and walking to school [36] are also associated with some objective 


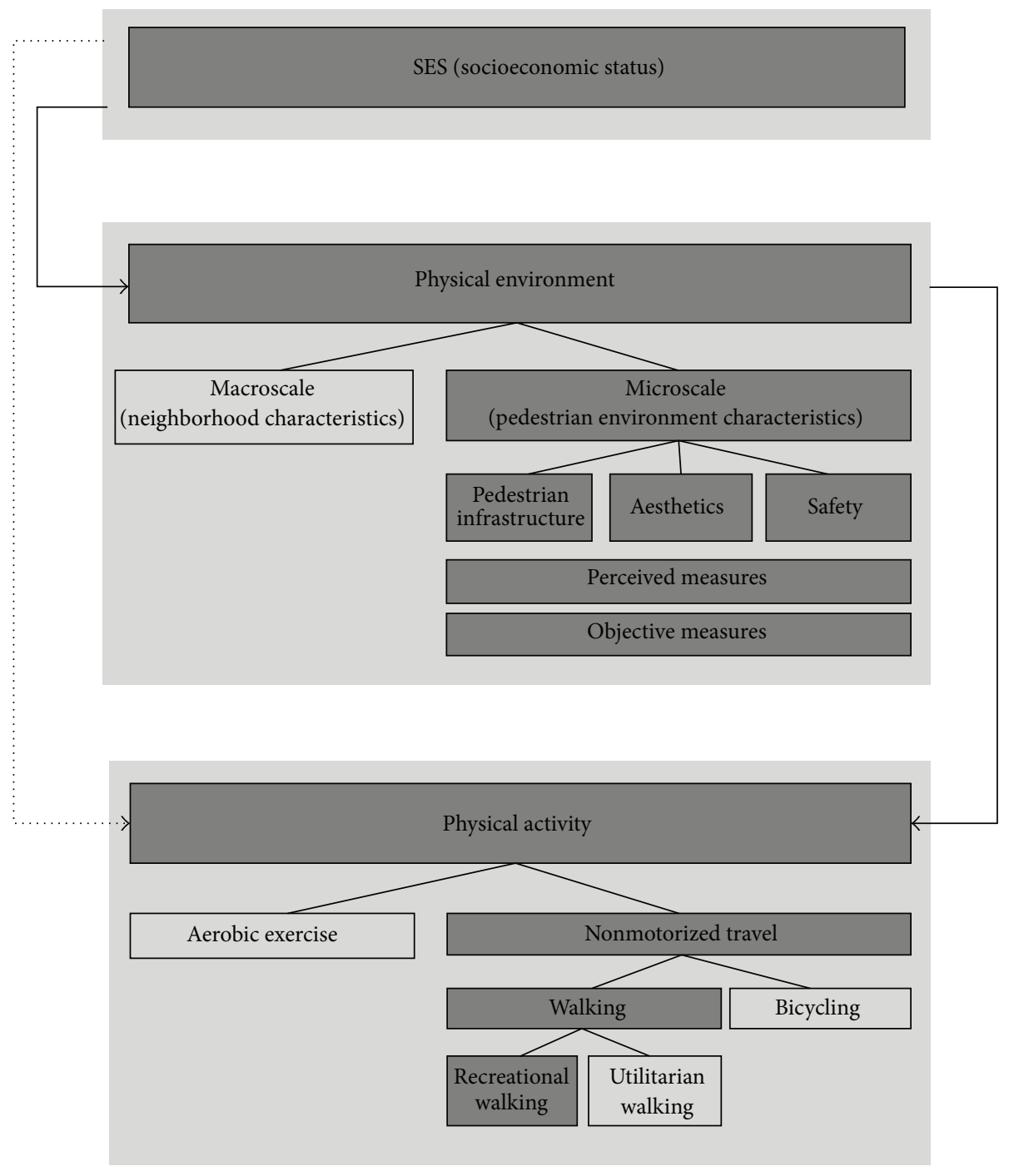

FIGURE 1: Literature map.

measures of physical environment characteristics. However, perceived street connectivity is not associated with utilitarian walking [29].

Recreational walking is different than utilitarian walking in relation to physical environment. Although some objective measures of physical environment characteristics are associated with recreational walking $[12,22]$, some are not, such as home age [31]. There is especially a poor agreement between objective and perceived measures of physical environment characteristics in relation to recreational walking [37]. A possible explanation is provided by a meta-analysis [2] which shows that a different set of objective measures (microscale rather than macroscale ones) are linked to recreational walking.

As suggested in the literature, recreational walking may be the type of physical activity which is associated with perceived microscale measures of physical environment characteristics. Therefore, this study addresses the relationship between perceived microscale measures of physical environment characteristics and recreational walking.
2.2. Measures of Physical Environment in relation to Physical Activity: Objective and Perceived Measures and Macro- and Microscale Measures. There are two types (perceived and objective) and two scales (micro and macro) of measures used for operationalizing physical environment characteristics. Perceived characteristics refer to residents' perception of the physical environment characteristics, whereas objective ones are those observed by the researchers using an audit tool. Both types of physical environment characteristics can be at either microscale (pedestrian environment) or macroscale (neighborhood).

The objective macroscale measures typically include distance, connectivity, land use, density, and age. All five of the objective neighborhood characteristics are frequently utilized in the literature. For example, distance has been shown to be associated with walking behavior (e.g., [17, 27, 32, 34]). More persistently, the positive affect of street connectivity with high intersection density on walking behavior has been demonstrated (e.g., [11, 12, 17, 24, 26-30, 32]). Regarding landuse measures, the variety of closely proximate nonresidential 
uses has also been repeatedly linked to walking behavior (e.g., [11-13, 15, 17, 18, 21, 22, 26, 27, 29, 30, 32, 34, 37]). Moreover, density (measured as either population density or residential density), as a neighborhood characteristic, has been shown to have associations with walking behavior (e.g., $[9,11,12,17,22,25-27,29,30,32,38])$. Finally, age (measured as either neighborhood age or home age) has been linked to walking behavior (e.g., $[9,31,38])$.

These five objective macroscale characteristics have been identified as characteristics which would foster or inhibit walking behavior. However, the variation in the associations between composite measures (a combination of these five measures) and walking behavior suggests that although these measures are useful, they should be supplemented with the microscale characteristics. For example, Frank et al. [26] suggest that the untested environmental variables in their study (such as presence of sidewalks) could help explain the variation beyond the $10 \%$ variation in physical activity, which was explained by a composite measure including three of the objective macroscale characteristics (land-use mix, residential density, and street connectivity). Similarly, Sallis et al. [8] argue that macroscale variables are insufficient in describing the physical activity affability of a neighborhood without the microscale variables.

Although they are less popularly utilized, objective microscale measures of pedestrian environment characteristics also have associations with physical activity. Pedestrian infrastructure (such as presence of sidewalks, crosswalks, and street lights), for example, has been linked to walking behavior $[13,18,21,22,30]$, as well as aesthetics $[13,15,30]$, traffic safety $[13,30,34]$, and crime safety $[21,28,30]$.

The overwhelming evidence provided for these five objective macroscale measures and three objective microscale measures is undermined by the conflicting results in the literature regarding objective and perceived measures of physical environments' association with walking behavior.

The perceived macroscale measures, which have associations with walking behavior, also include perceived distance [17], perceived access and/or proximity to nonresidential uses $[15,18,21,37]$, and perceived street connectivity [30].

Moreover, the perceived microscale measures, which have associations with walking behavior, include perceived pedestrian infrastructure (such as presence of sidewalks, crosswalks, and street lights) [21, 39], perceived aesthetics $[16,39]$, and perceived traffic safety $[14,21,39,40]$.

Although the elements of objective and perceived measures are similar for both macro- and microscale characteristics, there is poor agreement between objective and perceived measures of physical environment characteristics in relation to physical activity $[14,17,21,29,37]$. The conflicting results in the literature for objective and perceived measures of physical environment characteristics have been identified as a major problem especially because it is unclear which measure should be used to identify the point of intervention in the physical environment: people's perception or objective data [41]. However, recognizing that people's behavior (i.e., physical activity) will be affected by their perception of the built environment, which includes perceived qualities such as quantity and quality of greenery and aesthetics [42], rather than the built environment itself $[43,44]$, allows for recommending interventions to improve perceived characteristics [29].

In this study, perceived microscale characteristics are included not only for their potential role in the short term improvements of the physical environment to support better health, but also because previous research suggests better associations with recreational walking. Objective microscale characteristics are also included in this study because previous research suggests associations with walking behavior, although not specifically with recreational walking behavior.

2.2.1. The Walkability Audit Tool: Microscale Measures and Walkable Street Design Criteria. Discovering how to gather data on physical environment characteristics has been one of the fundamental struggles in this field of study. The variation of outcomes in studies depending on the scale (micro or macro) and type (perceived or objective) of measured physical environment characteristics in relation to different types of measured physical activity (recreational or utilitarian) has prompted many meta-analyses and reviews of multiple studies in attempts to summarize the results in relation to different measures utilized (such as $[1,2]$ ) or compare the audit tools (such as $[20,45,46]$ ).

A review of audit tools for gathering data on physical environment characteristics in relation to physical activity among adults reflects those ambiguities. For example, some audit tools were designed to measure both outdoor and indoor physical activity spaces for any type of physical activity (such as $[39,47]$ ). Other audit tools focus on outdoor physical activity spaces in relation to general physical activity but measure some elements of both macro- and microscale characteristics (such as $[46,48-50]$ ). Very few audit tools address one type of physical activity (i.e., recreational walking), although they include some elements of both macro- and microscale characteristics (such as $[30,51]$ ). When the challenge of incongruity between perceived and objective measures is added, there is increased variation among audit tools. There are researchers who attempt to compare perceived and objective measures at the macro- and microscale (such as [15]), while others address only the perceived characteristics (such as [50]) or only the objective characteristics (such as $[46,48])$ for both macro- and microscale measures.

Moreover, failing to address the contextual differences has been another problem with audit tools. For example, van Holle et al. [52] identify some elements of micro- and macroscale measures generally used in the North American and Australian studies which are irrelevant in the European context. Similarly, after reviewing the most frequently used European audit tools, which were edited versions of audit tools prepared for countries outside of Europe, Spittaels et al. [53] justify the need for a comprehensive audit tool for European cities and develop one for that purpose with the participation of international experts. With a similar concern, Cerin et al. [54] implement the most frequently used perceived micro- and macroscales measure audit tool in the literature, NEWS, in 12 countries in order to derive comparable country-specific measurement models. The results of this comprehensive study suggest that even after country-specific 
modifications are proposed to the original scoring protocol, some intercountry discrepancies still remain [54]. Part of the problem may be the format of the perception questions utilizing the Likert scale in audit tools. Inherent weaknesses of the Likert scale, such as its immeasurable sensitivity to the number of categories and the labels of categories, especially for cross-cultural comparisons, have not been addressed for their use in walkability audit tools. However, research shows that, especially for disadvantaged groups, Likert scale measurements fail to detect the meaning communicated in the free text accounts [55]. Therefore, an alternative approach with open-ended questions was utilized in this study for measuring perceived microscale characteristics and addressing the contextual differences between two SES sites.

Since use of composite measures of physical environment and broad definitions of physical activity are problematic in identifying the influence of physical environment on physical activity, this study focuses on one scale of the physical environment (microscale) and one type of physical activity (recreational walking). Therefore, the audit tools addressing the aforementioned variables were reviewed to develop the audit tool used in this study. Particularly elements discussed in studies in which associations were found between microscale characteristics and recreational walking behavior (such as $[30,51]$ ) were considered.

One of the most comprehensive comparisons of audit tools addressing microscale measures is done by Clifton et al. [46]. They compare six audit tools (Walking Suitability Assessment Form from UNC Chapel Hill, Walkable Places Survey from Baltimore Metropolitan Council, Analytic Audit Tool from Saint Louis University, Systematic Pedestrian and Cycling Environmental Scan from University of Western Australia, Irvine-Minnesota Inventory from University of California Irvine and University of Minnesota, and PBIC Checklist from Partnership for a Walkable America) along with their own audit tool (Pedestrian Environment Data Scan from University of Maryland, College Park). There are other audit tools similar to PBIC prepared for community members to conduct the assessment, such as NEWS (Neighborhood Environment Walkability Scale), PANES (Physical Activity Neighborhood Environment Scale), and DIY Community Street Audits, which also address microscale measures although not exclusive.

Other than these walkability audit tools, walkable-street design criteria have been developed in the urban planning literature. Although these criteria have not been tested as vigorously as the audit tools, they are justified with evidence from successful implementation.

The first principle of walkable street design, safe streets for pedestrians, includes criteria such as protecting the pedestrians from high-speed traffic while walking on the sidewalk or while crossing the street $[56,57]$ in addition to the criterion of safety from crime $[56,58]$. This principle is similar to the safety element of microscale measures.

The second principle, pleasant streets for pedestrians, includes human-scale streetscape configuration, positive sensory experiences $[56,57]$, and high perceptual complexity $[56,59]$. This principle includes elements related to aesthetics element of microscale measures.
The third principle, comfortable streets for pedestrians, includes accessibility, proper width of the walkable area without obstacles, surface quality of sidewalks, and short blocks with frequent connections, in addition to accommodating solitary and social activities [56, 59, 60]. This principle is similar to the pedestrian infrastructure element of microscale measures.

Among these elements, which are commonly included in the measures of various audit tools and listed in walkablestreet design criteria in the literature, 19 elements were selected to measure only objective microscale characteristics in this study. Inevitably, the elements measuring perceived and objective macroscale characteristics and those measuring perceived microscale characteristics were left out in this study. Instead, the perceived microscale characteristics were measured with open-ended questions in order to accommodate the complexity and locality of perceived characteristics expected to be found in two opposite SES neighborhoods.

However, two elements occasionally utilized in audit tools for objective microscale measures, traffic volume and architectural qualities, were not included in the current study due to the ambiguity of their effects on pedestrians' walking experience. In the literature, evidence of the influence of traffic volume on pedestrian safety is inconsistent, and operationalization of architectural qualities of buildings facing sidewalks is in progress.

Traffic volume has a considerable influence on crash frequency in traffic [61]. However, it is not included in models addressing pedestrian safety (e.g., [62]). Pedestrian safety models include elements related to the safety of pedestrian crossing rather than traffic volume, as traffic accidents involving pedestrians occur most frequently at street crossings, not in the moving traffic. Moreover, Ewing and Dumbaugh [63] suggest that lower volume traffic is worse for pedestrian safety contrary to the transportation planning principles.

Research on walkable environments has included architectural qualities with less than perfect operationalization, although a few genuine attempts have been made to improve it, for example, with the help of an expert panel [64]. However, operationalization of architectural qualities still needs further clarification, especially given the differences found in commercial and residential areas.

In this study, the walkability audit tool includes nine objective measures of traffic safety, three objective measures of aesthetics, and seven objective measures of pedestrian infrastructure. The elements of the audit tool are sidewalk presence (sidewalk continuity, paved width, and movable width), sidewalk quality (surface quality, parkway along sidewalk), inclines, crosswalk characteristics (crosswalk quality, crosswalk frequency, crosswalk safety, road crossing width, and median), curbside parking, speed limits, segment connectivity (length of the segment), traffic calming measures (physical separator on the sidewalk and on the street, speed control elements), street lighting, cleanliness, and shade.

\subsection{Role of Socioeconomic Status in relation to Physical} Environment and Physical Activity. The association between socioeconomic status (SES) and physical inactivity and consequently poor health has been firmly established. Low SES 
groups in the United States display these problems disproportionately more $[4-7,9,40]$. However, it is the influence of SES on macro- and microscale characteristics of the physical environment that makes the role of SES ambiguous in this framework.

The influence of SES on physical environment characteristics presents itself unmistakably through the macroscale measures. For example, higher density neighborhoods [8, 9], especially in urban areas [6], accommodate low SES groups primarily due to the affordability of housing in those areas. However, these macroscale characteristics, which are predominantly objective measures, characterize the low SES neighborhoods as more walkable.

The influence of SES on physical environment characteristics can also be seen through microscale measures. The low quality microscale characteristics, such as poorly maintained streets [10] and low levels of both traffic and crime safety [6], are found frequently in low SES neighborhoods. Kelly et al. [10] argue that there is more sidewalk unevenness, obstructions on sidewalks, and physical disorders in predominantly African American segments of study areas. GilesCorti and Donovan [65] also support this argument; their study illustrates that although perceived access to pedestrian facilities is high in low SES areas, perceived problems related to those facilities are many, such as traffic and visual appeal problems. These microscale characteristics, which include both objective and perceived measures, characterize the low SES neighborhoods as less walkable.

A combination of the influence of SES on micro- and macroscale physical environment characteristics is observed in the case of a particular land use: parks. Research shows that people living close to parks, especially to large and attractive parks, report more recreational minutes walking on average [66]: this is a macroscale measure (land use). Research also shows that low income and/or ethnic minority concentrated neighborhoods have poor access to parks [67, 68] and that those parks are not used to their potential in low SES neighborhoods, partially due to safety concerns $[69,70]$ : this is a microscale measure (safety). Access to green landscape has been discussed as a dividing element for high and low SES neighborhoods. Research shows that physical activity in nature produces better health outcomes [71] and that perceived positive qualities of green landscape affect more physical activity [42].

Moreover, there are behavior patterns which are seemingly associated with the physical environment but are fully or predominantly linked to SES. Use of alternative modes of transportation, which seems to suggest the presence of a better physical environment accommodating healthy behavior, for example, is usually due to the high cost of owning and driving a private car $[4,6]$. Also, lower levels of recreational walking for low SES groups [7] could be the result of allocating time to multiple jobs they have to hold [4] and not necessarily because of the poor quality of their recreational walking environment. For example, utilizing a refreshing methodology including focus groups, Eyler et al. [72] report that minority women identify personal barriers (lack of time) twice as many times as they do environmental barriers (lack of access and safety) to describe impediments to being physically more active. Then again, research also shows that some microscale characteristics do explain recreational walking behavior patterns (e.g., [2, 12, 22]), and SES might be the determining factor for the relationship between neighborhood walkability and physical activity [73].

There are also behavior patterns and physical environment characteristics which are not associated with SES. For example, according to Craig et al. [34] there is no association between SES and walking to work. Also, Sallis et al. [8] report that objective measures of physical environment characteristics which are supportive of walking behavior are not associated with income level. In fact, the slight relationship, they report, is reversed, suggesting that high-income neighborhoods are less supportive of walking behavior. Similarly, Giles-Corti and Donovan [65] state that quality of the walking environment may be more important than SES for walking behavior.

In this study, the role of SES is explored by comparing expected recreational walking in two opposite SES neighborhoods, regardless of physical environment. Furthermore, we compare their perceived and objective microscale physical environment characteristics, along with reported recreational walking and observed walking, which are in turn assumed to be influenced by aforementioned microscale characteristics.

\section{Methodology}

A case study design with a mixed-method approach was utilized. Two cities in one of the southwestern states in the United States, with nearly same-size population and with almost opposite SES (according to the 2010 Census), were selected. In the lower SES city, the population is more than $75 \%$ persons of Hispanic or Latino origin; less than $10 \%$ of the population holds a Bachelor's degree or higher; and the median household income is between $\$ 45,000$ and $\$ 49,999$. In the higher SES city, the population is more than $75 \%$ non-Hispanic White persons; more than $60 \%$ of the population holds a Bachelor's degree or higher; and the median household income is more than $\$ 100,000$.

Selection of two research sites from these two cities was based on the findings reported in the literature on associations between recreational walking and physical environment characteristics. As mentioned previously, the microscale variables are influential on people's recreational walking behavior [2]. However, one of the most frequently utilized macroscale measures, density, is an unusual physical environment characteristic for recreational walking behavior. For example, Forsyth et al. [74] show that higher density has a modest but negative effect on recreational walking, whereas Ewing et al. [12] conclude that residents of compact places report more recreational walking than residents of sprawling places. Given the ambiguous role of density in the literature (the only macroscale measure with some influence on recreational walking) and the focus of this study on microscale measures due to evidence in the literature for their influence on recreational walking, the site selection was chosen appropriately. Inevitably, in two different SES cities in the same region, the macroscale characteristics are different. 


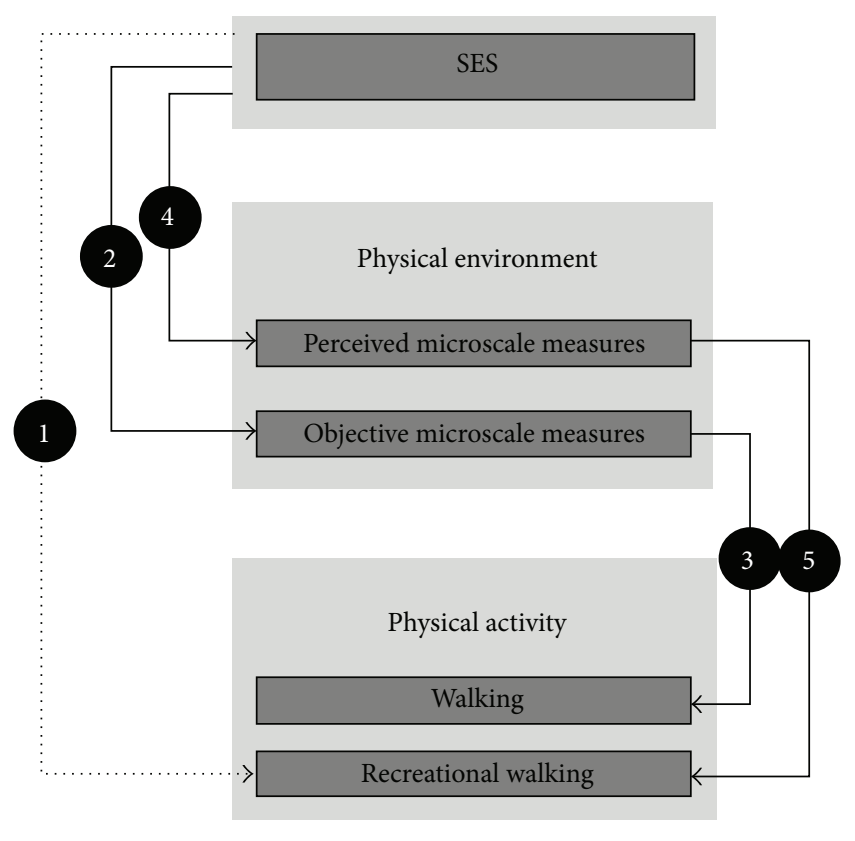

FIgURE 2: Research model.

Population density in the low SES city is approximately five times more dense than the population density in the high SES city. As it is not clear if high density or low density has a positive effect on recreational walking, the purpose of the study was to include cities with similar numbers of residents who might potentially be walking for recreation. Therefore, research sites were selected to cover areas in each city to include a similar number of residents. The research site was approximately 0.6 square miles in the low SES city, and it was approximately 3 square miles in the high SES city. Moreover, in both research sites, one commercial street, one elementary school, and at least one public park were within one-mile radius. Additionally, street connectivity is higher in the low SES city. Consequently, the total length of street segments included in the low SES city (approximately 18 miles) is less than the total length of street segments included in the high SES city (approximately 36 miles).

Two cases with opposite SES were included in the study to compare (1) expected recreational walking regardless of physical environment, (2) objective microscale characteristics and (3) their influence on observed walking, and (4) perceived microscale characteristics and (5) their influence on reported recreational walking. The research model in Figure 2 shows the conceptual framework for this study.

The expected recreational walking, regardless of physical environment in two research sites, was determined according to median household income level and National Household Travel Survey (NHTS 2009) data.

The objective microscale characteristics were recorded by utilizing a 19-item audit tool, which was prepared based on similar tools in the literature and which includes measures of pedestrian infrastructure, aesthetics, and traffic safety (the Appendix). Nine objective measures of traffic safety were included in the walkability audit tool: crosswalk frequency, quality, safety, road crossing width, median, speed limit, speed control elements, and physical separators between the traffic lanes and the sidewalk. Three objective measures of aesthetics were included in the walkability audit tool: parkways along sidewalks, shade, and cleanliness. Finally, the audit tool included seven elements of objective measures of pedestrian infrastructure: continuity, length, paved width, clear width, surface quality, inclines, and street lights. The audit tool was utilized to collect information on a total of 441 street segments: 276 in the high SES city and 165 in the low SES city. Each street segment was identified between two consecutive intersections.

Walking was also observed for each of these street segments, with an additional item in the walkability audit tool for the number of pedestrians on the sidewalks. The pedestrian counts were recorded in 10-minute intervals for every street segment.

Each street segment received a score of one or zero for each of the elements in the walkability audit tool. The conditions which constitute one or zero were described explicitly. For example, regarding continuity, a one score indicated that there was a sidewalk on both sides throughout a street segment, and a zero score indicated that there was at least one section of the sidewalk missing on either side (the Appendix).

The audits were conducted simultaneously by two researchers. One researcher made the observations while the other recorded the information on an audit sheet for each street segment. Therefore, there was no need for alignment between the two auditors for consistency. The audits were completed in five consecutive weekdays between $10 \mathrm{am}$ and $4 \mathrm{pm}$.

The data for perceived microscale characteristics and reported recreational walking was gathered with an assessment questionnaire. The questionnaire included open-ended questions about perceived quality of the microscale characteristics and time spent for recreational walking. To measure the perceived quality of the microscale characteristics, respondents were asked to identify two best and two worst characteristics of sidewalks and streets in their neighborhood. To measure time spent for recreational walking, respondents were asked how much time they spend walking outdoors for leisure on a typical day.

The questionnaire was administered to a total of 133 pedestrians: 65 from the high SES city and 68 from the low SES city. The respondents were selected utilizing opportunity sampling, where the researcher reaches out for the respondents that are available and are familiar with the physical environment of interest [75]. The pedestrians on sidewalks walking on the street segments identified for the audit were approached and only those who were residents in those cities were administered a questionnaire. Therefore, representativeness beyond being typical pedestrians of those cities was not sought in selecting the respondents.

\section{Analysis and Findings}

Expected recreational walking, objective and perceived microscale characteristics, observed walking (pedestrian 
TABLE 1: Walking behavior and pedestrian environment characteristics.

\begin{tabular}{lcc}
\hline & High SES site & Low SES site \\
\hline $\begin{array}{l}\text { Average walkability audit } \\
\text { score } \\
\text { (out of 20 points) }\end{array}$ & $\begin{array}{c}10.7 \\
(N=276)\end{array}$ & $\begin{array}{c}13.5 \\
(N=165)\end{array}$ \\
\hline $\begin{array}{l}\text { Average number of } \\
\text { pedestrians on the sidewalks } \\
\text { (per minute) }\end{array}$ & $\begin{array}{c}0.97 \\
(N=276)\end{array}$ & $\begin{array}{c}3.32 \\
(N=165)\end{array}$ \\
\hline $\begin{array}{l}\text { Average time spent for } \\
\text { recreational walking } \\
\text { (per day) }\end{array}$ & 15 minutes & 30 minutes \\
\hline
\end{tabular}

counts), and reported recreational walking time were analyzed and compared in two almost opposite SES research sites. The research model in Figure 2 shows the relationships for which the following findings are reported.

(1) The expected recreational walking, regardless of physical environment, was higher in the high SES city than the low SES city. According to the National Household Travel Survey (NHTS 2009), for the income bracket of the low SES city $(\$ 45,000-\$ 49,999)$ the annual person miles for walk trips with social or recreational purpose (976.72 million) are almost one-fourth of the annual person miles for walk trips with social or recreational purpose $(3,878.37$ million) for the income bracket of the high SES city $(>\$ 100,000)$.

(2) A comparison of objective microscale characteristics, that is, walkability audit scores, of two research sites showed that the high SES site had lower objective walkability (Table 1). The items related to traffic safety were especially problematic (Figure 1 and Table 2).

(3) Overall a higher number of pedestrians were observed in the low SES city (Table 1).

(4) A content analysis of the perceived microscale characteristics demonstrated similarities as well as differences between low and high SES residents' perceptions (Table 3). There is a perceived deficiency of sidewalks and crosswalks only in the high SES site. There is also better perceived aesthetic characteristics in the low SES site.

(5) The average reported time spent for recreational walking on a typical day in the low SES city was more than the time reported in the high SES city (Table 1).

The higher average of reported recreational walking time in the low SES site was unexpected given the recreational walking difference according to the NHTS 2009 data for each income bracket. It is important to emphasize that the questionnaires were not conducted with a sample seeking for representativeness in terms of demographic characteristics. Also, the small sample size makes the average time spent for recreational walking even less representative. Moreover, overreporting is one of the problems associated with self-reported physical activity data. In particular, given the fact that the questionnaire respondents were selected among those who were already walking on the sidewalks at these sites, it is highly likely that the residents who walk on a regular basis were selected for the questionnaires. These might also explain why the absolute average time reported for recreational walking in the low SES site is higher than the recommended physical activity time by Center for Disease Control (150 minutes per week). Therefore, the comparison made here is not based on the absolute values of NHTS data and questionnaire data. Any sampling bias and over-reporting problems that may have affected the average reported recreational walking time in the low SES site are expected to have also affected the average reported recreational walking time in the high SES site. Consequently, the relative difference between the high SES and the low SES sites for reported recreational walking and for NHTS data is suggestive of an unusual situation. Without influence of the physical environment (according to the NHTS data), the SES suggests less recreational walking for the residents of the low SES site than for the residents of the high SES site. However, the residents of the high SES site walk recreationally less than those of the low SES site, potentially due to the influence of the physical environment characteristic (which are assumed to be microscale in this study) of both sites.

Two possibilities were considered as potential explanations of this unexpected difference and further analysis was conducted accordingly. First, the high SES site might have unusually disadvantageous microscale characteristics to undermine the residents' recreational walking behavior. Second, the low SES site might have unusually advantageous microscale characteristics to encourage the residents' recreational walking behavior. Objective and perceived microscale characteristics were further analyzed to identify possible impediments in the high SES research site hindering recreational walking and possible catalysts in the low SES research site fostering recreational walking.

The objective microscale measures are shown in Figure 3 as the scores of the walkability audits of both research sites. It is evident that the low SES site audit scores are almost consistently higher than those of the high SES site. However, for some items (crosswalk quality, physical separation on sidewalk, and speed control elements) the gap in average item scores is wider between two sites. Table 2 shows examples of those positive characteristics in the low SES site and the negative ones in the high SES site.

Considering the possibility that lower scores of objective microscale measures in the high SES site might be undermining recreational walking, the association between objective measures and pedestrian counts was analyzed.

The correlation between 19 -item walkability audit scores and pedestrian counts shows that the objective measures of pedestrian environment characteristics can explain only $15 \%$ of the variation of the number of pedestrians on the sidewalks (correlation coefficient $[r]=0.392285$, statistically significant at $99 \%$ level, $N=441$ ).

However, when only those walkability audit elements, which are problematic in either of or both research sites, are included, the correlation is stronger. The abridged set of walkability audit elements (circled in Figure 3) includes only seven, which received average scores less than the average score of all elements (0.61) in either of or both research sites. These seven more problematic objective microscale measures are crosswalk frequency, crosswalk quality, crosswalk safety, median, physical separator on the sidewalk, physical 
TABLE 2: Examples of microscale measures with a wide gap in average item scores between high and low SES sites.

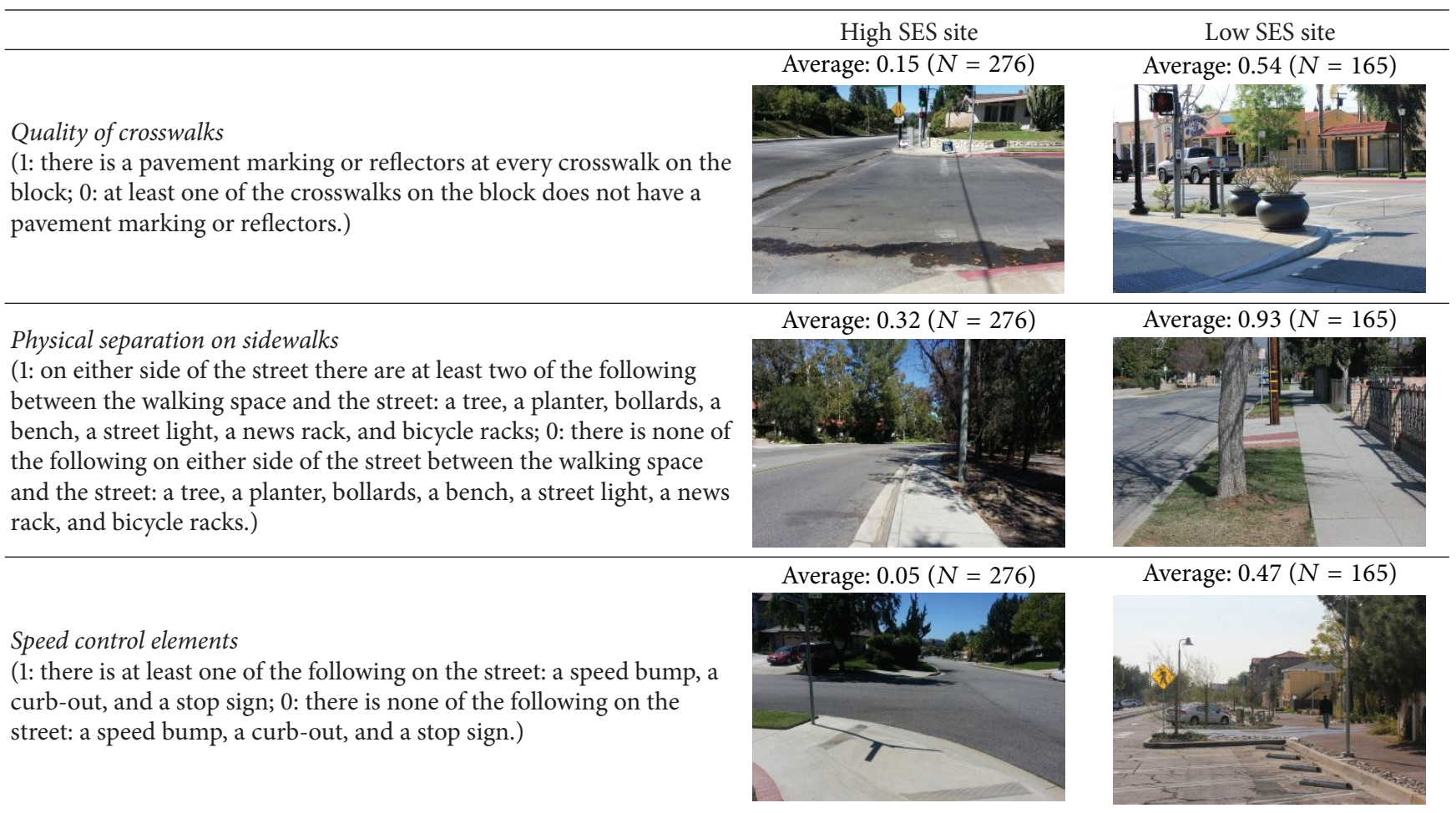

TABLE 3: Perceived microscale characteristics.

\begin{tabular}{|c|c|c|c|}
\hline & & $\begin{array}{l}\text { High SES site } \\
\quad(N=65)\end{array}$ & $\begin{array}{l}\text { Low SES site } \\
\qquad(N=68)\end{array}$ \\
\hline \multirow{5}{*}{$\begin{array}{l}\text { Perceived } \\
\text { best characteristics of the pedestrian environment }\end{array}$} & Cleanliness & $18 \%$ & $12 \%$ \\
\hline & Safety & $17 \%$ & $12 \%$ \\
\hline & Quietness & $17 \%$ & $3 \%$ \\
\hline & Greenery & $15 \%$ & $7 \%$ \\
\hline & Aesthetics & $6 \%$ & $15 \%$ \\
\hline \multirow{2}{*}{ Perceived worst characteristics of the pedestrian environment } & Deficient sidewalks and crosswalks & $25 \%$ & $0 \%$ \\
\hline & Lack of shade & $15 \%$ & $32 \%$ \\
\hline
\end{tabular}

separator on the street, speed control elements, and streetlights, three of which are also identified in Table 2 as those elements with the widest gap in walkability audit scores of two sites.

The correlation between these seven-item walkability audit scores and pedestrian counts shows that more problematic objective microscale characteristics can explain $29 \%$ of the variation of the number of pedestrians on the sidewalks (correlation coefficient $[r]=0.542003$, statistically significant at $99 \%$ level, $N=441$ ).

It is important to note that almost all of these more problematic characteristics are related to traffic safety, suggesting that traffic safety might be part of the microscale characteristics hindering recreational walking in the high SES site.

In addition to the objective microscale measures, the perceived microscale measures are helpful in understanding the possible impediments and catalysts for walking at the research sites.
A content analysis was conducted to analyze the openended question responses to the most favorite and the least favorite characteristics questions. Table 3 shows similarities and differences between low and high SES residents' perceptions of microscale characteristics. Respondents identified aesthetics as one of the best pedestrian environment characteristics, more in the low SES site $(15 \%)$ than in the high SES site (6\%). Similarly cleanliness (12\%) and safety (12\%) were identified as two best characteristics in the low SES site and more so in the high SES site (18\% and 17\%, resp.). Both quietness and greenery were identified as best characteristics, more in the high SES site (17\% and 15\%, resp.) than in the low SES site (3\% and 7\%, resp.).

One of the worst characteristics in the high SES site was identified as deficient sidewalks and crosswalks by $25 \%$ of the respondents. It was not mentioned as a problem in the low SES site. However, lack of shade was a problem in both sites: $15 \%$ in the high SES site and 32\% in the low SES site (Table 3). 


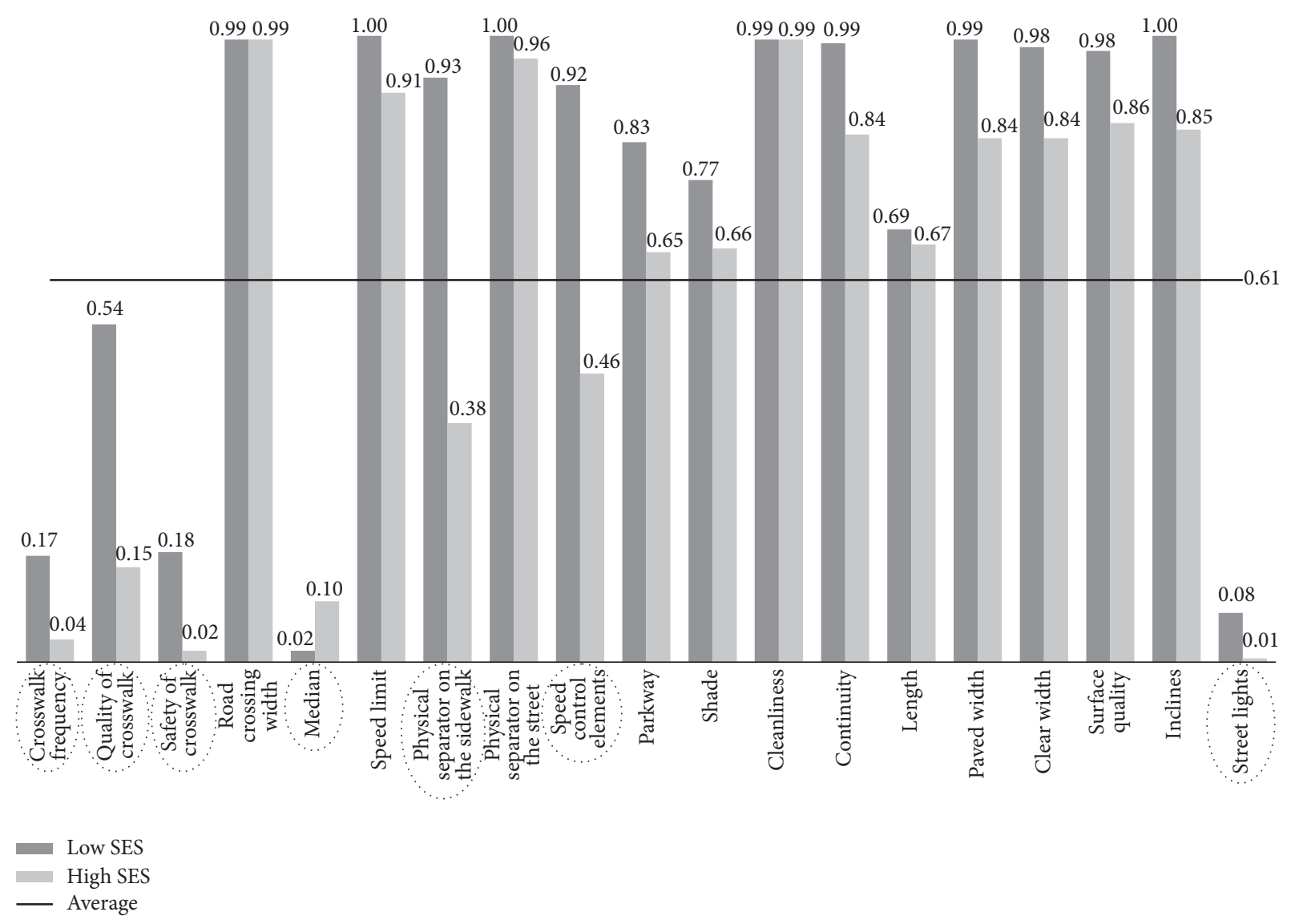

FIGURE 3: Walkability audit score averages, where one represents more walkable environments and zero represents less walkable environments (for low SES site $N=165$; for high SES site $N=276$; for average $N=441$ ).

Perceived microscale characteristics also provide a partial explanation for the possible catalyst in the low SES site encouraging recreational walking. Evidently, in the low SES site, residents have a positive perception of their pedestrian environment, with only one major complaint: lack of shade. Although the high SES respondents also have a positive perception of their pedestrian environment, one of the problems they perceive might be more hindering than lack of shade: deficient sidewalks and crosswalks.

Given the finding based on objective measures only (walkability audit tool) which suggest the high SES pedestrian environment is problematic due to traffic safety problems, clearly $25 \%$ of the respondents perceive a similar problem (Table 3).

Traffic safety problem in the high SES site is one of the aligned elements between objective and perceived microscale measures. For the measure of aesthetics, however, not all the elements are aligned between objective and perceived measures. One of the aesthetics elements, cleanliness, is objectively and perceptually high in both sites. Yet, another one of the aesthetics elements, shade, has above average objective scores in both sites, although perceptually lack of shade is a problem in both sites. Similarly, most of the pedestrian infrastructure elements have above average objective scores in high SES site, although the respondents perceive the sidewalks as deficient.
However, the common elements of best perceived characteristics at both research sites (cleanliness, safety, quietness, greenery, and aesthetics) (Table 3) suggest that despite the differences in objective measures, residents perceive similar characteristics as positive which might be the real catalysts for recreational walking.

\section{Conclusion}

Findings of this study suggest that SES alone has less influence than microscale physical environment characteristics for recreational walking and that when objectively and perceptually microscale characteristics are better in a low SES site, more recreational walking happens. Possible explanations include objective and perceived impediments in the higher SES site and objective and perceived catalysts in the lower SES site. Some of these findings are supported by previous studies' findings in the literature.

According to the NHTS 2009, a higher SES suggests longer time spent recreationally in walking. According to the findings of this study, however, if the objective and perceived microscale environment characteristics are right, a lower SES group might spend more than the expected amount of time recreationally walking.

In this study, the objective microscale characteristics, especially those related to traffic safety, were found to have 
a correlation with observed walking (pedestrian counts). This correlation also supports the finding that as the respondents reported spending less time in recreational walking at the high SES site, they also perceived more problematic microscale characteristics, especially those related to traffic safety.

The same correlation is also parallel to the arguments in the literature on objective microscale characteristics and walking behavior. According to the literature, objective measures of pedestrian infrastructure (e.g., presence of sidewalks, crosswalks, and street lights) are associated with walking behavior $[13,18,21,22,30]$, as well as objective measures of aesthetics $[13,15,30]$, and objective measures of traffic safety $[13,30,34]$.

Thus, a possible impediment at the high SES site for recreational walking is objective and perceived traffic related problems. Also, positively perceived aesthetics might be a catalyst in the low SES site for recreational walking.

This association between positively perceived microscale characteristics and the high amount of observed and reported walking behavior is also aligned with previous research. According to the literature, perceived measures of pedestrian environment characteristics, which have associations with walking behavior, include perceived pedestrian infrastructure (such as presence of sidewalks, crosswalks, and street lights) [21, 39], perceived aesthetics [16, 39], and perceived traffic safety $[14,21,39,40]$.

The importance of perceived microscale characteristics in relation to recreational walking is also parallel to the literature. It is argued that not only are the environmental characteristics associated with walking for recreation different than those associated with walking for utilitarian purposes $[2,15]$, but also perceived environmental characteristics are more influential than the objective ones for recreational walking behavior $[29,30]$.

This argument is further supported in the literature with an emphasis on the influence of positive feelings such as comfort and relaxation on perceived aesthetic qualities, which in return affect spatial behaviors [44]. In this case positive perceived pedestrian environment characteristics affect recreational walking. In particular, greenery and aesthetics, which are two of the perceived best characteristics in both high and low SES neighborhoods, have been shown to be important catalysts for physical activity $[42,71]$.

However, better objective and perceived microscale characteristics at the low SES site are at odds with the previous research. The literature suggests that low SES neighborhoods have perceived and/or objective microscale characteristics of a less walkable environment (e.g., $[6,10,65]$ ), such as poor aesthetics, maintenance, and safety. However, according to the findings of this study, overall objective microscale characteristics of the low SES site are better than those of the high SES site. In particular both objective and perceived elements related to traffic safety are more indicative of this difference. Moreover, the findings of this study show that perceived microscale characteristics related to aesthetics (aesthetics, cleanliness, quietness, and greenery) are similar in two sites, although slightly higher percentages of respondents identified more of those elements as best characteristics in the high SES site.

In this study, two microscale characteristics are aligned between perceived and objective measures (i.e., traffic safety and cleanliness), whereas one microscale characteristic (i.e., shade) is not. This finding is also parallel to the literature. It is argued that although some objective measures of physical environment characteristics are associated with recreationbased walking $[12,22]$, there is especially a poor agreement between objective and perceived measures of physical environment characteristics in relation to recreational walking [37].

Three main findings of this study support other studies in the literature. First, objective and perceived microscale characteristics influence walking behavior in general. Objective and perceived traffic safety problem undermines observed walking and reported recreational walking in high SES site; objective and perceived good aesthetics and pedestrian infrastructure foster observed walking and reported recreational walking in the low SES site. Second, perceived characteristics of the physical environment are more influential on recreational walking than the objective ones. Although the overall walkability audit scores suggest objectively a more walkable pedestrian environment in the low SES site, the perceived characteristics help further explain the difference in recreational walking. Third, there is a poor agreement between objective and perceived pedestrian environment characteristics for recreational walking behavior. There is a disagreement between the objective and perceived pedestrian environment characteristics for elements of shade in both sites and pedestrian infrastructure in the high SES site.

Two main findings of this study contrast with arguments in the literature. First, microscale characteristics are not better in the high SES site. On the contrary, overall objective and perceived microscale characteristics are better in the low SES site. Second, more recreational walking was not reported in the high SES site. The reported time spent for recreational walking is higher in the low SES site. These two findings are also the main contribution of this study to the literature. The unexpectedly better objective and perceived microscale characteristics of this specific low SES site might be the reason for the unexpectedly higher average reported recreational walking. Therefore, it is the conclusion of this study that, with the help of the microscale physical environment characteristics, people might walk recreationally beyond what their SES suggests.

Some poor objective and perceived pedestrian environment characteristics of the high SES site, which are unexpected for the SES level, may be the impediment lessening the recreational walking time of the residents. Also, surprisingly positive objective and perceived microscale characteristics of the low SES site may be the catalyst adding to the recreational walking time of the residents.

5.1. Limitations. There are several limitations of this study. First, compared to similar studies on walkability assessment, the respondent group for perceived microscale characteristics in this study is small, providing limited data despite the open-ended nature of the questions. Second, although 
TABLE 4: Walkability audit tool.

\begin{tabular}{|c|c|c|c|}
\hline & Item & 1 & 0 \\
\hline \multirow{9}{*}{ Traffic safety } & $\begin{array}{l}\text { Crosswalk } \\
\text { frequency }\end{array}$ & $\begin{array}{l}\text { The distance between the nearest two } \\
\text { crosswalks is at least } 400 \text { feet. }\end{array}$ & $\begin{array}{l}\text { The distance between the nearest two crosswalks } \\
\text { is more than } 400 \text { feet. }\end{array}$ \\
\hline & $\begin{array}{l}\text { Quality of } \\
\text { crosswalk }\end{array}$ & $\begin{array}{l}\text { There is a pavement marking or reflectors } \\
\text { at every crosswalk on the block. }\end{array}$ & $\begin{array}{l}\text { At least one of the crosswalks on the block does } \\
\text { not have a pavement marking or reflectors. }\end{array}$ \\
\hline & Safety of crosswalk & $\begin{array}{l}\text { There are automated or prompted traffic } \\
\text { lights or in-roadway warning lights for } \\
\text { crossing at every crosswalk on the block. }\end{array}$ & There are no lights at a crosswalk on the block. \\
\hline & $\begin{array}{l}\text { Road crossing } \\
\text { width }\end{array}$ & $\begin{array}{l}\text { There are no more than } 6 \text { traffic lanes } \\
\text { including curbside parking. }\end{array}$ & $\begin{array}{l}\text { There are more than } 6 \text { traffic lanes including } \\
\text { curbside parking. }\end{array}$ \\
\hline & Median & There is a median traffic island. & There is no median traffic island. \\
\hline & Speed limit & $\begin{array}{l}\text { The speed limit is less than or equal to } \\
30 \mathrm{mph} \text {. }\end{array}$ & The speed limit is more than $30 \mathrm{mph}$. \\
\hline & $\begin{array}{l}\text { Physical separator } \\
\text { on the sidewalk }\end{array}$ & $\begin{array}{l}\text { On either side of the street there are at } \\
\text { least two of the following between the } \\
\text { walking space and the street: a tree, a } \\
\text { planter, bollards, a bench, a street light, a } \\
\text { news rack, and bicycle racks. }\end{array}$ & $\begin{array}{l}\text { There is none of the following on either side of the } \\
\text { street between the walking space and the street: a } \\
\text { tree, a planter, bollards, a bench, a street light, a } \\
\text { news rack, and bicycle racks. }\end{array}$ \\
\hline & $\begin{array}{l}\text { Physical separator } \\
\text { on the street }\end{array}$ & $\begin{array}{l}\text { On either side of the street there is at least } \\
\text { one of the following: curbside parking, } \\
\text { bike lane. }\end{array}$ & $\begin{array}{l}\text { There is none of the following on either side of the } \\
\text { street: curbside parking, bike lane. }\end{array}$ \\
\hline & $\begin{array}{l}\text { Speed control } \\
\text { elements }\end{array}$ & $\begin{array}{l}\text { There is at least one of the following on } \\
\text { the street: a speed bump, a curb-out, and } \\
\text { a stop sign. }\end{array}$ & $\begin{array}{l}\text { There is none of the following on the street: a } \\
\text { speed bump, a curb-out, and a stop sign. }\end{array}$ \\
\hline \multirow{3}{*}{ Aesthetics } & $\begin{array}{l}\text { Parkway along } \\
\text { sidewalk width }\end{array}$ & $\begin{array}{l}\text { There is at least one portion of the } \\
\text { sidewalk with an ADDITIONAL width of } \\
\text { grass or dirt surface on either side. }\end{array}$ & $\begin{array}{l}\text { There is no ADDITIONAL width of grass or dirt } \\
\text { surface to the sidewalk on either side. }\end{array}$ \\
\hline & Shade & $\begin{array}{l}\text { There are shade trees (more than one) or } \\
\text { awnings at least on one side of the street. }\end{array}$ & $\begin{array}{l}\text { There are no shade trees or awnings on either side } \\
\text { of the street. }\end{array}$ \\
\hline & Cleanliness & $\begin{array}{l}\text { There is no trash or graffiti on either side } \\
\text { of the street. }\end{array}$ & $\begin{array}{l}\text { There is trash and/or graffiti on at least one side of } \\
\text { the street. }\end{array}$ \\
\hline \multirow{8}{*}{$\begin{array}{l}\text { Pedestrian } \\
\text { infrastructure }\end{array}$} & Continuity & $\begin{array}{l}\text { There is a sidewalk on both sides } \\
\text { throughout the block. }\end{array}$ & $\begin{array}{l}\text { There is at least one section of the sidewalk } \\
\text { missing on either side. }\end{array}$ \\
\hline & Length & $\begin{array}{l}\text { The length of the block is NOT more than } \\
400 \text { feet. }\end{array}$ & The length of the block is more than 400 feet. \\
\hline & Paved width & $\begin{array}{l}\text { There is at least } 5 \text { feet of PAVED surface } \\
\text { on the sidewalk on both sides. }\end{array}$ & $\begin{array}{l}\text { There is at least one section of the sidewalk less } \\
\text { than } 5 \text { feet PAVED surface on either side. }\end{array}$ \\
\hline & Clear width & $\begin{array}{l}\text { There is at least } 5 \text { feet of CLEAR (without } \\
\text { obstacles) paved surface on the sidewalk } \\
\text { on both sides. }\end{array}$ & $\begin{array}{l}\text { There is at least one section of the sidewalk less } \\
\text { than } 5 \text { feet CLEAR (without obstacles) paved } \\
\text { surface on either side. }\end{array}$ \\
\hline & Surface quality & $\begin{array}{l}\text { The surface of the sidewalk is smooth on } \\
\text { both sides throughout the block. }\end{array}$ & $\begin{array}{l}\text { There is at least one section of the sidewalk with } \\
\text { cracks on either side. }\end{array}$ \\
\hline & Inclines & $\begin{array}{l}\text { There is at least one portion of the street } \\
\text { on the block with steep incline. }\end{array}$ & $\begin{array}{l}\text { No portion of the street on the block has a steep } \\
\text { incline. }\end{array}$ \\
\hline & Street lights & The street lights are pedestrian scale. & $\begin{array}{l}\text { The street lights are for the traffic only or they are } \\
\text { not pedestrian scale. }\end{array}$ \\
\hline & $\begin{array}{l}\text { Pedestrian count } \\
\text { (for } 10 \text { minutes) }\end{array}$ & $\begin{array}{l}\text { On a typical day there are at least } 4 \text { people } \\
\text { per minute on either side of the street. }\end{array}$ & $\begin{array}{l}\text { On a typical day there are less than } 4 \text { people per } \\
\text { minute on either side of the street. }\end{array}$ \\
\hline
\end{tabular}

the open-ended questions in the questionnaire provided the opportunity for two such different groups of respondents to express their opinions without being restricted with the previously established concepts, specific elements of the pedestrian infrastructure, for example, were not mentioned by the respondents. Therefore, comparing the objective and perceived microscale characteristics item by item was not possible. The audit tool designed for this study, focusing on only the microscale characteristics and especially recreational walking, suffers from one of the common problems of this type of audit tool: poor operationalization of aesthetics. Consequently, the elements included in the audit tool to measure aesthetics are not aligned with perceived characteristics reported by the residents. 


\section{Appendix}

See Table 4.

\section{Conflict of Interests}

The author declares that there is no conflict of interests regarding the publication of this paper.

\section{Acknowledgments}

This research was conducted with the support which the author received as the Research Fellow of the College of Social and Behavioral Sciences at California State University, Northridge, in the 2011-12 academic year. In addition to the author's release time from teaching, the fellowship also funded their two research assistants (Arsen Dervishian and Matthew Azpilicueta), to whom the author is indebted for their meticulous work.

\section{References}

[1] N. Humpel, N. Owen, and E. Leslie, "Environmental factors associated with adults' participation in physical activity. A review," The American Journal of Preventive Medicine, vol. 22, no. 3, pp. 188-199, 2002.

[2] G. McCormack, B. Giles-Corti, A. Lange, T. Smith, K. Martin, and T. J. Pikora, "An update of recent evidence of the relationship between objective and self-report measures of the physical environment and physical activity behaviours," Journal of Science and Medicine in Sport, vol. 7, no. 1, pp. 81-92, 2004.

[3] D. Ding, J. F. Sallis, J. Kerr, S. Lee, and D. E. Rosenberg, "Neighborhood environment and physical activity among youth," American Journal of Preventive Medicine, vol. 41, no. 4, pp. 442455, 2011.

[4] L. D. Frank, P. O. Engelke, and T. L. Schmid, Health and Community Design: The Impact of the built Environment on Physical Activity, Island Press, Washington, DC, USA, 2003.

[5] D. A. Barr, Health Disparities in the United States: Social Class, Race, Ethnicity, and Health, The Johns Hopkins University Press, Baltimore, Md, USA, 2008.

[6] R. P. Lopez and P. H. Hynes, "Obesity, physical activity, and the urban environment: public health research needs," in Urban Health: Readings in the Social, Built, and Physical Environments of U.S. Cities, H. P. Hynes and R. Lopez, Eds., pp. 169-185, Jones \& Bartlett, Boston, Mass, USA, 2009.

[7] T. H. M. Keegan, S. Hurley, D. Goldberg et al., "The association between neighborhood characteristics and body size and physical activity in the california teachers study cohort," American Journal of Public Health, vol. 102, no. 4, pp. 689-697, 2012.

[8] J. F. Sallis, D. J. Slymen, T. L. Conway et al., "Income disparities in perceived neighborhood built and social environment attributes," Health \& Place, vol. 17, no. 6, pp. 1274-1283, 2011.

[9] C. D. Zick, K. R. Smith, J. X. Fan, B. B. Brown, I. Yamada, and L. Kowaleski-Jones, "Running to the Store? The relationship between neighborhood environments and the risk of obesity," Social Science and Medicine, vol. 69, no. 10, pp. 1493-1500, 2009.

[10] C. M. Kelly, M. Schootman, E. A. Baker, E. K. Barnidge, and A. Lemes, "Evidence-Based Public Health Policy and Practice: the association of sidewalk walkability and physical disorder with area-level race and poverty," Journal of Epidemiology and Community Health, vol. 61, no. 11, pp. 978-983, 2007.

[11] K. Sundquist, U. Eriksson, N. Kawakami, L. Skog, H. Ohlsson, and D. Arvidsson, "Neighborhood walkability, physical activity, and walking behavior: the Swedish Neighborhood and Physical Activity (SNAP) study," Social Science and Medicine, vol. 72, no. 8, pp. 1266-1273, 2011.

[12] R. Ewing, T. Schmid, R. Killingsworth, A. Zlot, and S. Raudenbush, "Relationship between urban sprawl and physical activity, obesity, and morbidity," American Journal of Health Promotion, vol. 18, no. 1, pp. 47-57, 2003.

[13] B. Giles-Corti and R. J. Donovan, "Relative influences of individual, social environmental, and physical environmental correlates of walking," The American Journal of Public Health, vol. 93, no. 9, pp. 1583-1589, 2003.

[14] A. P. McGinn, K. R. Evenson, A. H. Herring, S. L. Huston, and D. A. Rodriguez, "Exploring associations between physical activity and perceived and objective measures of the built environment," Journal of Urban Health, vol. 84, no. 2, pp. 162-184, 2007.

[15] C. M. Hoehner, L. K. Brennan Ramirez, M. B. Elliott, S. L. Handy, and R. C. Brownson, "Perceived and objective environmental measures and physical activity among urban adults," The American Journal of Preventive Medicine, vol. 28, no. 2, pp. 105116, 2005.

[16] N. Humpel, N. Owen, D. Iverson, E. Leslie, and A. Bauman, "Perceived environment attributes, residential location, and walking for particular purposes," American Journal of Preventive Medicine, vol. 26, no. 2, pp. 119-125, 2004.

[17] G. R. McCormack, E. Cerin, E. Leslie, L. du Toit, and N. Owen, "Objective versus perceived walking distances to destinations: correspondence and predictive validity," Environment and Behavior, vol. 40, no. 3, pp. 401-425, 2008.

[18] L. Lin and A. V. Moudon, "Objective versus subjective measures of the built environment, which are most effective in capturing associations with walking?" Health and Place, vol. 16, no. 2, pp. 339-348, 2010.

[19] J. F. Sallis, "Measuring physical activity environments. A brief history," American Journal of Preventive Medicine, vol. 36, no. 4, supplement, pp. S86-S92, 2009.

[20] R. C. Brownson, C. M. Hoehner, K. Day, A. Forsyth, and J. F. Sallis, "Measuring the built environment for physical activity. State of the science," The American Journal of Preventive Medicine, vol. 36, no. 4, pp. S99.e12-S123.e12, 2009.

[21] K. A. Kirtland, D. E. Porter, C. L. Addy et al., "Environmental measures of physical activity supports: perception versus reality," The American Journal of Preventive Medicine, vol. 24, no. 4, pp. 323-331, 2003.

[22] R. Cervero and K. Kockelman, "Travel demand and the 3Ds: density, diversity, and design," Transportation Research Part D: Transport and Environment, vol. 2, no. 3, pp. 199-219, 1997.

[23] T. R. Berry, J. C. Spence, C. M. Blanchard, N. Cutumisu, J. Edwards, and G. Selfridge, "A longitudinal and cross-sectional examination of the relationship between reasons for choosing a neighbourhood, physical activity and body mass index," International Journal of Behavioral Nutrition and Physical Activity, vol. 7, article 57, 2010.

[24] R. Cervero, O. L. Sarmiento, E. Jacoby, L. F. Gomez, and A. Neiman, "Influences of built environments on walking and cycling: lessons from Bogotá," International Journal of Sustainable Transportation, vol. 3, no. 4, pp. 203-226, 2009. 
[25] F. L. Garden and B. B. Jalaludin, "Impact of urban sprawl on overweight, obesity, and physical activity in Sydney, Australia," Journal of Urban Health, vol. 86, no. 1, pp. 19-30, 2009.

[26] L. D. Frank, T. L. Schmid, J. F. Sallis, J. Chapman, and B. E. Saelens, "Linking objectively measured physical activity with objectively measured urban form: findings from SMARTRAQ," The American Journal of Preventive Medicine, vol. 28, no. 2, supplement 2, pp. 117-125, 2005.

[27] C. Lee and A. V. Moudon, "The 3Ds + R: quantifying land use and urban form correlates of walking," Transportation Research Part D: Transport and Environment, vol. 11, no. 3, pp. 204-215, 2006.

[28] S. Doyle, A. Kelly-Schwartz, M. Schlossberg, and J. Stockard, "Active community environments and health: the relationship of walkable and safe communities to individual health," Journal of the American Planning Association, vol. 72, no. 1, pp. 19-32, 2006.

[29] K. Gebel, A. E. Bauman, T. Sugiyama, and N. Owen, "Mismatch between perceived and objectively assessed neighborhood walkability attributes: prospective relationships with walking and weight gain," Health \& Place, vol. 17, no. 2, pp. 519-524, 2011.

[30] B. E. Saelens, J. F. Sallis, J. B. Black, and D. Chen, "Neighborhood-based differences in physical activity: an environment scale evaluation," The American Journal of Public Health, vol. 93, no. 9, pp. 1552-1558, 2003.

[31] D. Berrigan and R. P. Troiano, "The association between urban form and physical activity in U.S. adults," American Journal of Preventive Medicine, vol. 23, no. 2, pp. 74-79, 2002.

[32] N. Owen, E. Cerin, E. Leslie et al., "Neighborhood walkability and the walking behavior of Australian adults," American Journal of Preventive Medicine, vol. 33, no. 5, pp. 387-395, 2007.

[33] M. E. McConville, D. A. Rodríguez, K. Clifton, G. Cho, and S. Fleischhacker, "Disaggregate land uses and walking," American Journal of Preventive Medicine, vol. 40, no. 1, pp. 25-32, 2011.

[34] C. L. Craig, R. C. Brownson, S. E. Cragg, and A. L. Dunn, "Exploring the effect of the environment on physical activity: a study examining walking to work," The American Journal of Preventive Medicine, vol. 23, no. 2, pp. 36-43, 2002.

[35] E. Cerin, L. D. Frank, J. F. Sallis et al., "From neighborhood design and food options to residents' weight status," Appetite, vol. 56, no. 3, pp. 693-703, 2011.

[36] B. Giles-Corti, G. Wood, T. Pikora et al., "School site and the potential to walk to school: the impact of street connectivity and traffic exposure in school neighborhoods," Health \& Place, vol. 17, no. 2, pp. 545-550, 2011.

[37] K. Ball, R. W. Jeffery, D. A. Crawford, R. J. Roberts, J. Salmon, and A. F. Timperio, "Mismatch between perceived and objective measures of physical activity environments," Preventive Medicine, vol. 47, no. 3, pp. 294-298, 2008.

[38] C. M. Hoehner, S. L. Handy, Y. Yan, S. N. Blair, and D. Berrigan, "Association between neighborhood walkability, cardiorespiratory fitness and body-mass index," Social Science \& Medicine, vol. 73, no. 12, pp. 1707-1716, 2011.

[39] R. C. Brownson, E. A. Baker, R. A. Housemann, L. K. Brennan, and S. J. Bacak, "Environmental and policy determinants of physical activity in the United States," American Journal of Public Health, vol. 91, no. 12, pp. 1995-2003, 2001.

[40] T. R. Berry, J. C. Spence, C. Blanchard, N. Cutumisu, J. Edwards, and C. Nykiforuk, "Changes in BMI over 6 years: the role of demographic and neighborhood characteristics," International Journal of Obesity, vol. 34, no. 8, pp. 1275-1283, 2010.
[41] C. M. Kelly, C. M. Hoehner, E. A. Baker, L. K. Brennan Ramirez, and R. C. Brownson, "Promoting physical activity in communities: approaches for successful evaluation of programs and policies," Evaluation and Program Planning, vol. 29, no. 3, pp. 280-292, 2006.

[42] S. de Vries, S. M. E. van Dillen, P. P. Groenewegen, and P. Spreeuwenberg, "Streetscape greenery and health: stress, social cohesion and physical activity as mediators," Social Science \& Medicine, vol. 94, pp. 26-33, 2013.

[43] A. Rapoport, Meaning of the Built Environment: A Nonverbal Communication Approach, Sage, Beverly Hills, Calif, USA, 1982.

[44] A. Ataov, "Environmental aesthetics," Journal of Planning Literature, vol. 13, no. 2, pp. 239-257, 1998.

[45] T. G. Townshend and A. A. Lake, "Relationships between 'wellness centre' use, the surrounding built environment and obesogenic behaviours, Sunderland, UK," Journal of Urban Design, vol. 16, no. 3, pp. 351-367, 2011.

[46] K. J. Clifton, A. D. L. Smith, and D. Rodriguez, “The development and testing of an audit for the pedestrian environment," Landscape and Urban Planning, vol. 80, no. 1-2, pp. 95-110, 2007.

[47] R. E. Lee, K. M. Booth, J. Y. Reese-Smith, G. Regan, and H. H. Howard, "The Physical Activity Resource Assessment (PARA) instrument: evaluating features, amenities and incivilities of physical activity resources in urban neighborhoods," International Journal of Behavioral Nutrition and Physical Activity, vol. 2, no. 1, article 13, 2005.

[48] T. J. Pikora, F. C. L. Bull, K. Jamrozik, M. Knuiman, B. Giles-Corti, and R. J. Donovan, "Developing a reliable audit instrument to measure the physical environment for physical activity," American Journal of Preventive Medicine, vol. 23, no. 3, pp. 187-194, 2002.

[49] C. Millington, C. W. Thompson, D. Rowe et al., "Development of the scottish walkability assessment tool (SWAT)," Health and Place, vol. 15, no. 2, pp. 474-481, 2009.

[50] K. Day, M. Boarnet, M. Alfonzo, and A. Forsyth, “The irvineminnesota inventory to measure built environments development," American Journal of Preventive Medicine, vol. 30, no. 2, pp. 144-152, 2006.

[51] K. Ball, A. Bauman, E. Leslie, and N. Owen, "Perceived environmental aesthetics and convenience and company are associated with walking for exercise among Australian adults," Preventive Medicine, vol. 33, no. 5, pp. 434-440, 2001.

[52] V. van Holle, B. Deforche, J. van Cauwenberg et al., "Relationship between the physical environment and different domains of physical activity in European adults: a systematic review," BMC Public Health, vol. 12, no. 1, article 807, 2012.

[53] H. Spittaels, C. Foster, J.-M. Oppert et al., "Assessment of environmental correlates of physical activity: development of a European questionnaire," International Journal of Behavioral Nutrition and Physical Activity, vol. 6, no. 1, article 39, 2009.

[54] E. Cerin, T. L. Conway, K. L. Cain et al., "Sharing good NEWS across the world: developing comparable scores across 12 countries for the neighborhood environment walkability scale (NEWS)," BMC Public Health, vol. 13, no. 1, article 309, 2013.

[55] J. Ogden and J. Lo, "How meaningful are data from Likert scales? An evaluation of how ratings are made and the role of the response shift in the socially disadvantaged," Journal of Health Psychology, vol. 17, no. 3, pp. 350-361, 2012.

[56] J. Gehl, Cities for People, Island Press, London, UK, 2010.

[57] A. B. Jacobs, E. Macdonald, and Y. Rofe, The Boulevard Book: History, Evolution, Design of Multiway Boulevards, The MIT Press, Cambridge, Mass, USA, 2002. 
[58] D. Farr, Sustainable Urbanism: Urban Design with Nature, Wiley, Hoboken, NJ, USA, 2008.

[59] A. Rapoport, "Pedestrian street use: culture and perception," in Public Streets for Public Use, A. V. Moudon, Ed., pp. 80-92, Van Nostrand Reinhold Company, New York, NY, USA, 1987.

[60] D. Appleyard, Livable Streets, University of California Press, Berkeley, Calif, USA, 1981.

[61] L. Aarts and I. van Schagen, "Driving speed and the risk of road crashes: a review," Accident Analysis and Prevention, vol. 38, no. 2, pp. 215-224, 2006.

[62] O. Basile, L. Persia, and D. S. Usami, "A methodology to assess pedestrian crossing safety," European Transport Research Review, vol. 2, no. 3, pp. 129-137, 2010.

[63] R. Ewing and E. Dumbaugh, "The built environment and traffic safety: a review of empirical evidence," Journal of Planning Literature, vol. 23, no. 4, pp. 347-367, 2009.

[64] R. Ewing and S. Handy, "Measuring the unmeasurable: urban design qualities related to walkability," Journal of Urban Design, vol. 14, no. 1, pp. 65-84, 2009.

[65] B. Giles-Corti and R. J. Donovan, "Socioeconomic status differences in recreational physical activity levels and real and perceived access to a supportive physical environment," Preventive Medicine, vol. 35, no. 6, pp. 601-611, 2002.

[66] T. Sugiyama, J. Francis, N. J. Middleton, N. Owen, and B. GilesCortI, "Associations between recreational walking and attractiveness, size, and proximity of neighborhood open spaces," American Journal of Public Health, vol. 100, no. 9, pp. 1752-1757, 2010.

[67] J. Wolch, J. P. Wilson, and J. Fehrenbach, "Parks and park funding in Los Angeles: an equity-mapping analysis," Urban Geography, vol. 26, no. 1, pp. 4-35, 2005.

[68] L. C. Abercrombie, J. F. Sallis, T. L. Conway, L. D. Frank, B. E. Saelens, and J. E. Chapman, "Income and racial disparities in access to public parks and private recreation facilities," The American Journal of Preventive Medicine, vol. 34, no. 1, pp. 9-15, 2008.

[69] D. A. Cohen, B. Han, K. P. Derose et al., "Neighborhood poverty, park use, and park-based physical activity in a Southern California city," Social Science and Medicine, vol. 75, no. 12, pp. 2317-2325, 2012.

[70] A. Loukaitou-Sideris, "Is it safe to walk? Neighborhood safety and security considerations and their effects on walking," Journal of Planning Literature, vol. 20, no. 3, pp. 219-232, 2006.

[71] T. P. Pasanen, L. Tyrväinen, and K. M. Korpela, "The relationship between perceived health and physical activity indoors, outdoors in built environments, and outdoors in nature," Applied Psychology: Health and Well-Being, vol. 6, no. 3, pp. 324346, 2014.

[72] A. A. Eyler, E. Baker, L. Cromer, A. C. King, R. C. Brownson, and R. J. Donatelle, "Physical activity and minority women: a qualitative study," Health Education and Behavior, vol. 25, no. 5, pp. 640-652, 1998.

[73] F. de Meester, D. van Dyck, I. de Bourdeaudhuij, B. Deforche, J. F. Sallis, and G. Cardon, "Active living neighborhoods: is neighborhood walkability a key element for Belgian adolescents?" BMC Public Health, vol. 12, no. 1, article 7, 2012.

[74] A. Forsyth, J. M. Oakes, K. H. Schmitz, and M. Hearst, "Does residential density increase walking and other physical activity?" Urban Studies, vol. 44, no. 4, pp. 679-697, 2007.

[75] J. L. Nasar, "Assessing perceptions of environments for active living," The American Journal of Preventive Medicine, vol. 34, no. 4, pp. 357-363, 2008. 

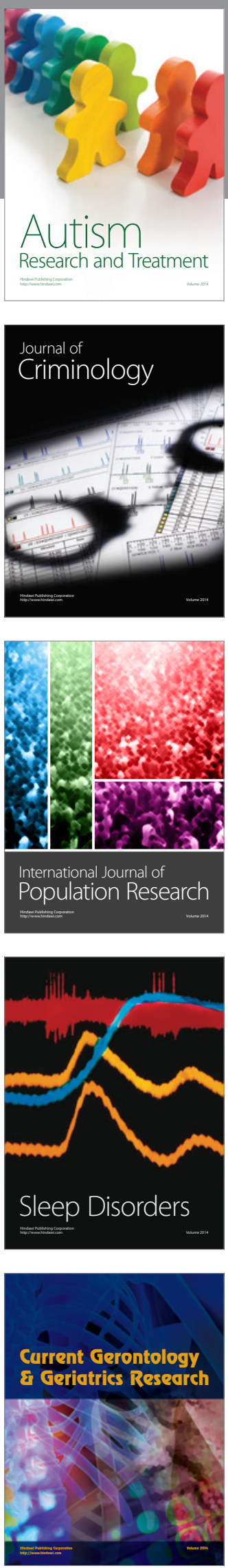
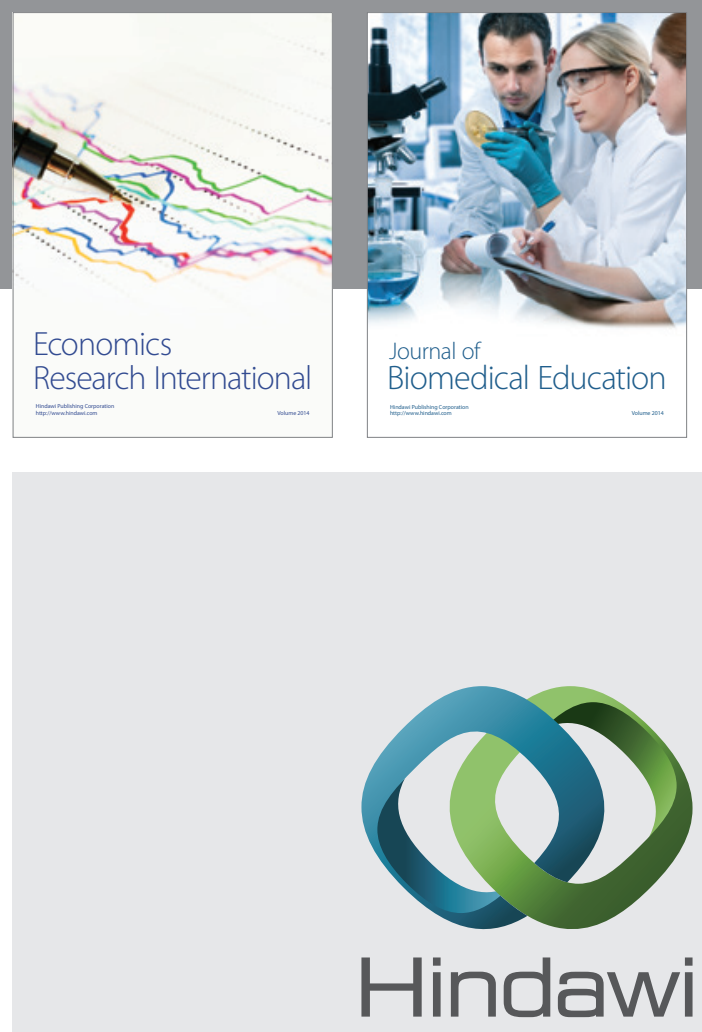

Submit your manuscripts at

http://www.hindawi.com
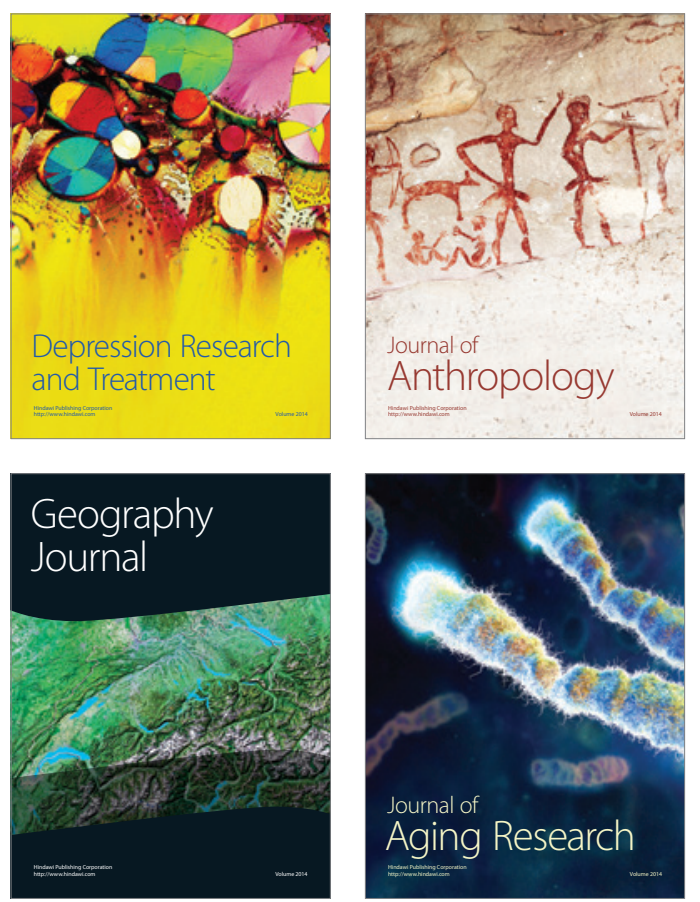
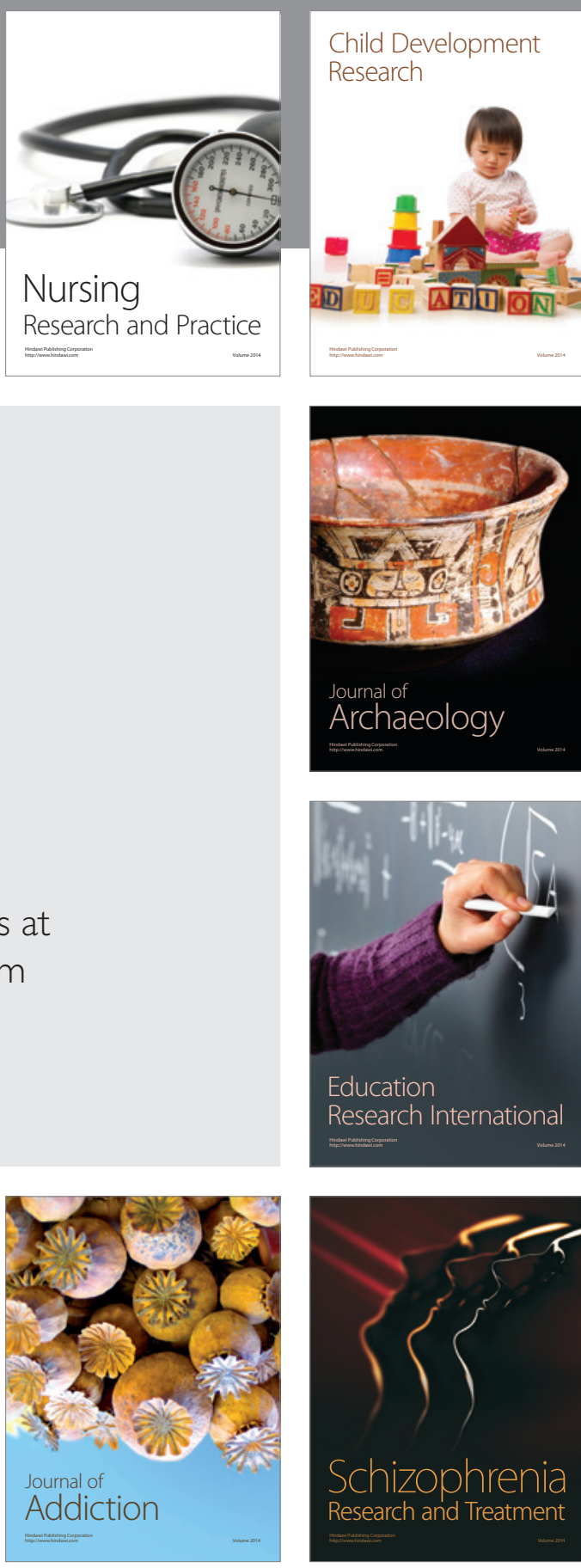

(D)
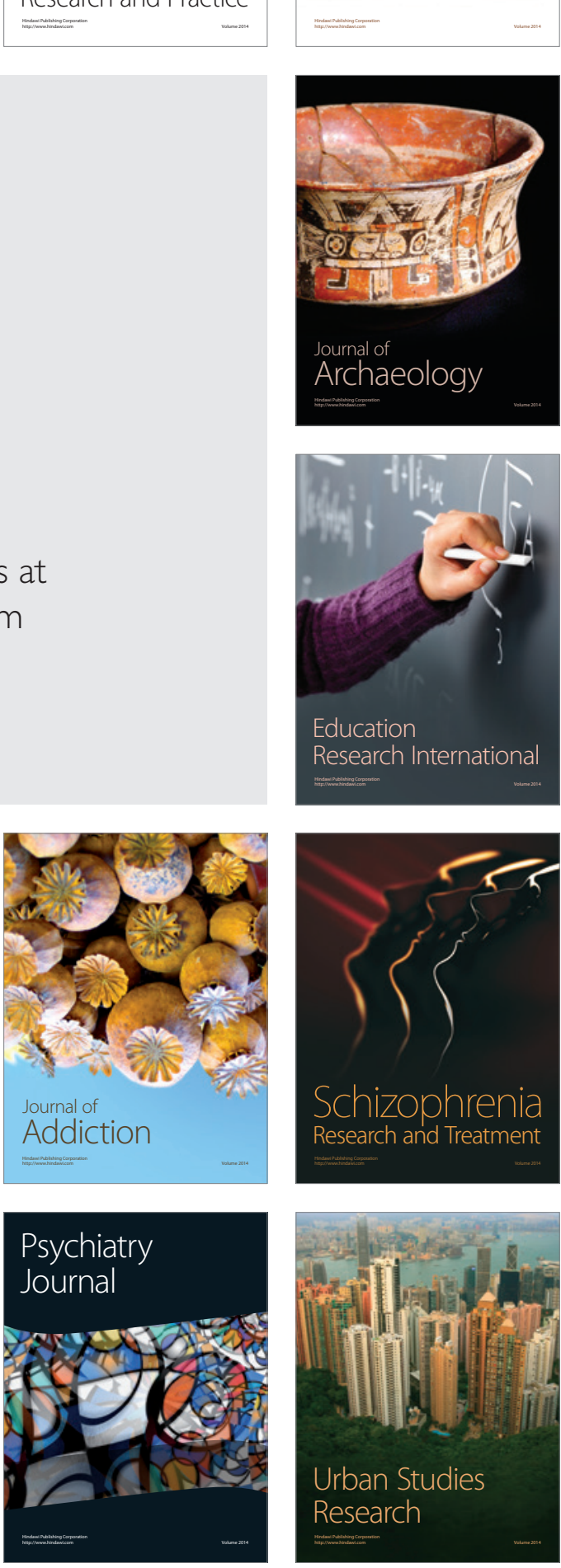